\title{
Exploitation problems and diagnostic of heat recovery steam boiler OU-192
}

\author{
Grzegorz Olewicz ${ }^{1}$, Adrian Sobczyszyn ${ }^{2, *}$, Kamil Staszałek ${ }^{3}$, and Przemystaw Syty ${ }^{4}$ \\ ${ }^{1}$ EDF Polska S.A., Cracow, Poland \\ 2,3,4Research and Technological Services "Pro Novum" Ltd.
}

\begin{abstract}
Combined Cycle Gas Turbine (CCGT) use exhaust gases from gas turbine (GT), which in basic systems are ejected to environment as discharge loss, for steam generation in Heat Recovery Steam Generator (HRSG). Higher unit efficiency achieved inter alia by using in boiler low and high pressure circuit allow to greater use of turbine exhaust gases enthalpy. Modular design solutions with tight structure, preferred on construction site, may be a problematic for maintenance services during operation and overhauls. This paper presents general operational problems of HRSG as well as detailed solutions for boiler OU-192. We discuss scope and results of diagnostic tests required to assess technical condition of the pressure elements, after 100000 hours operation, with the support of the software LM System $\mathrm{PRO}+$.
\end{abstract}

\section{Combined Cycle Gas Turbine and Heat Recovery Steam Generators in power engineering}

Technical and thermodynamic connection between gas and steam cycles allows a significant increase in the efficiency of energy conversion, particularly for cogeneration. In open gas turbine cycle power supplied to circuit is significant, but due the high temperature of exhaust gases, large part of it is discharged (as loss) to environment. In steam circuit, maximum process temperature is relatively low but from thermodynamic point of view, important is low temperature of exhaust gases [1]. Connecting these two circuits and using GT exhaust gases enthalpy for steam generation in HRSG the losses are minimalized. This is very important in both economic and environmental point of view. The main advantages of CCGT are:

- low investment cost compared to conventional coalfired units,

- shorter time of investment due the modular structure of main elements,

- high flexibility,

- high efficiency affecting the operation costs,

- lower pollutant emission compared to conventional coal-fired units.

High gas prices on Polish fuel market are main disadvantages of using CCGT and significantly affect economic balance.

Construction of HRSG is similar to the construction of conventional coal-fired boiler - it consists of economizer, evaporator and superheaters. The differences arise from principles of HRSG operation and its thermodynamic properties. Generally, these boilers can divided by:

- directions of exhaust gases flow,

- number of separate circuits with different working pressure.

In horizontal oriented boilers exhaust gases flow through horizontal channel with vertical located heating surfaces tubes, while in vertical oriented boilers exhaust gases flow through vertical channel with horizontal located heating surfaces tubes.

The use of more than one separate circuits with different working pressure is thermodynamically justified and it is intended to reduce losses. Apart from one pressure circuit we can find two- or even threepressure circuits. In this case, each circuit has a separate economizer, evaporator (also with separate drums) and superheaters.

Each of heating surfaces together with headers has a modular construction. Such structure can be problematic in certain situations, which occurs during operation. Modular construction which is favourable during investment stage and warranty full module exchange becomes problematic when one of elements fails. Constructor did not assume enough space required for local repairs within one module (eg. Evaporator). When element fails it requires extensive intervention in structure.

\section{HRSG exploitation problems}

Long-term operation of HRSG in power industry and industry all over the world, provides great operational

\footnotetext{
* Corresponding author: a.sobczyszyn@ pronovum.pl
} 
experience. In this chapter, due to limited space, we will present two interesting cause of the boiler failure.

One of the most common and often commented in literature problem is flow accelerated corrosion (FAC) on inner surfaces of heat exchangers tubes. FAC mechanism is based on destructive effect of vigorous flow of water or steam which damages and destroys protective oxide layer. In the place where the oxide layer is destroyed, exposed metal corrodes by creating a new layer of oxide. This process is then repeated until the thinning of the wall which leads to failure. In early stage, before failure, characteristic and extensive damages of tube inner surface can be observed. FAC mechanism depends on:

- water/steam quality,

- water/steam temperature,

- disturbances in the flow,

- metal chemical composition.

FAC in HRSG, as mentioned before, is a leading cause of damage. Frequent start-ups and work in cyclic mode has a negative influence over water quality which results in increase the risk of FAC. Also, corrosion products are transported with water/steam to further parts of circuit and they become deposits which can be another source of corrosion problems [2].

Another complex problem in HRSG is lack of or insufficient compensation of thermal expansion of tubes. It leads not only to tube damages, but also can result in serious failures of stubs and headers. Tube exposed on high temperature increases its length, which in spite of a theoretical heat extension margin, can result in buckling. This affects additional stress on header stubs. During operation, tube repeatedly changes its length, which generates an alternating stress and leads to fatigue failures [3,4]. Also, excessive constant stress, caused by bend ovalization together with corrosive environment leads to intensification of destructive corrosion and stress processes. In the result, micro-pitting occurs on privileged locations and elements such as bend with excessive ovalization $(>8 \%)$ [5].

These reasons of failures are only small part of mechanisms which can occur during HRSG operation. It is worth mentioning, that cyclic operation in case of HRSG, which were designed for stationary operation, can lead to intensification of negative processes leading to failure [4].

\section{Description of OU-192 type boiler}

Heat recovery steam boiler is a part of combined cycle gas turbine (CCGT). It uses the exhaust gas which flows in horizontal channel over each components inside. The boiler consists of two separate modules low-pressure (LP) and high-pressure (HP) circuits with natural flow. Major parts of boiler:

- HP superheater II,

- HP superheater I,

- wall-tubes with HP drum,

- HP economizer II,
- LP superheater,

- wall-tubes with LP drum,

- HP economizer I,

- LP economizer.

Only in high-pressure circuit - superheater and economizer are two-graded. Both of modules are ended by main outlet headers.

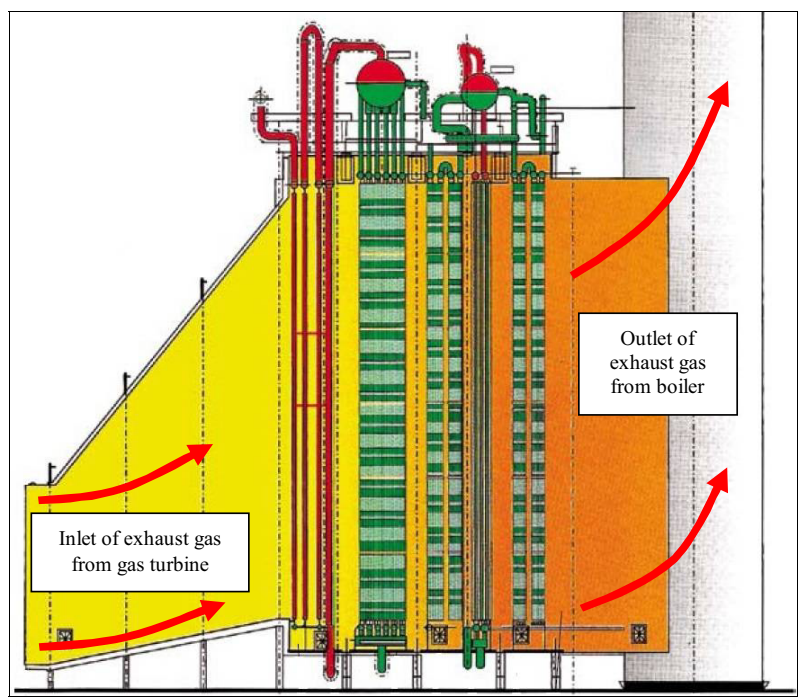

Fig. 1. Heat recovery steam boiler OU-192 type - profile [6].

\section{Working conditions analysis supported by life management software on the OU-192 type boiler}

Software platform LM System $\mathrm{PRO}+{ }^{\circledR}$ was installed in 2010 yr. It allows to register history of exploitation, working parameters and failure analysis needed to determine technical conditions of boiler elements. Based on the program data are charts of pressure and temperature for low- and high-pressure drums and superheater II (fig. $2 \div 4$ ). Construction and exploitation values are placed in table 1 , comparison between register data and assumed values are placed in table 2 .

Table 1. Construction and exploitation data of OU-192 type boiler [7].

\begin{tabular}{|c|c|}
\hline \multicolumn{2}{|c|}{ Construction data } \\
\hline Performance, $\mathrm{t} / \mathrm{h}$ & 192 \\
\hline Steam pressure (HP), MPa & 7,51 \\
\hline Steam temperature $(\mathrm{HP}),{ }^{\circ} \mathrm{C}$ & 505 \\
\hline Steam pressure (LP), MPa & 0,71 \\
\hline \multicolumn{2}{|c|}{ Construction data } \\
\hline Steam temperature $(\mathrm{LP}),{ }^{\circ} \mathrm{C}$ & 213,5 \\
\hline Performance, $\mathrm{t} / \mathrm{h}$ & 192 \\
\hline Steam pressure (HP), MPa & 7,51 \\
\hline \multicolumn{2}{|c|}{ Exploitation data } \\
\hline Total work time, hours & ca. 100000 \\
\hline Number of start-up & 246 \\
\hline Number of failures & 8 \\
\hline Number of pressure tests & 30 \\
\hline
\end{tabular}




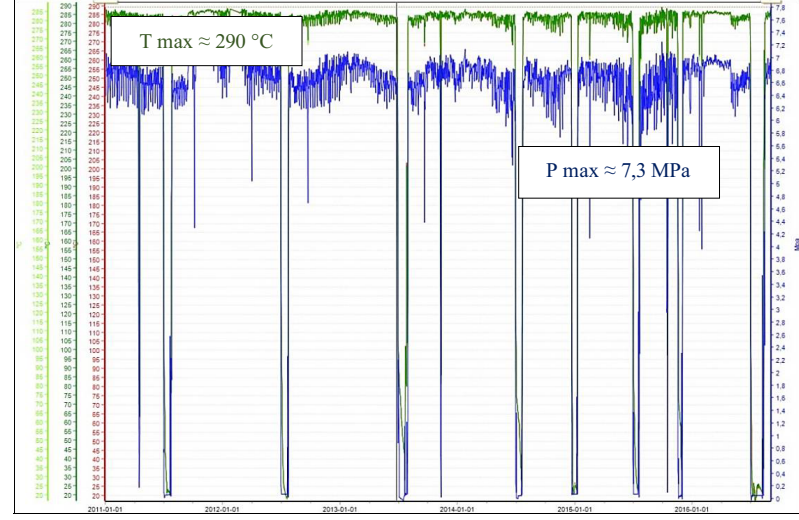

Fig. 2. Chart of metal temperature (upper holes area - center, left side, right side) with steam pressure - HP drum.

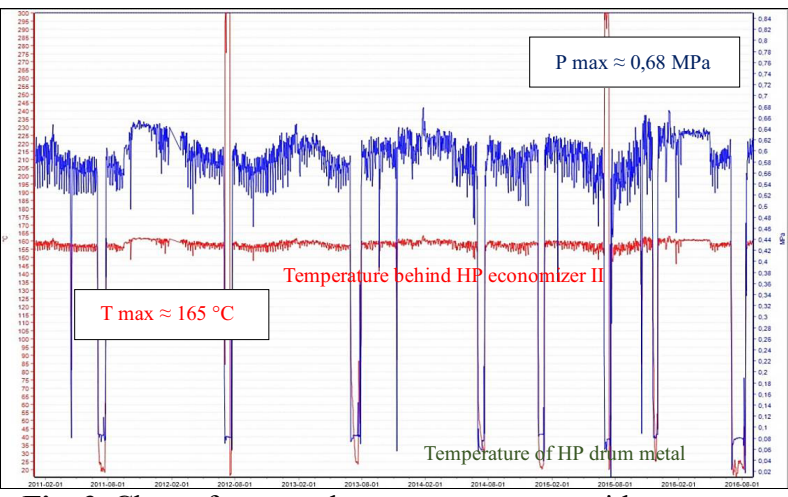

Fig. 3. Chart of saturated steam temperature with pressure LP drum.

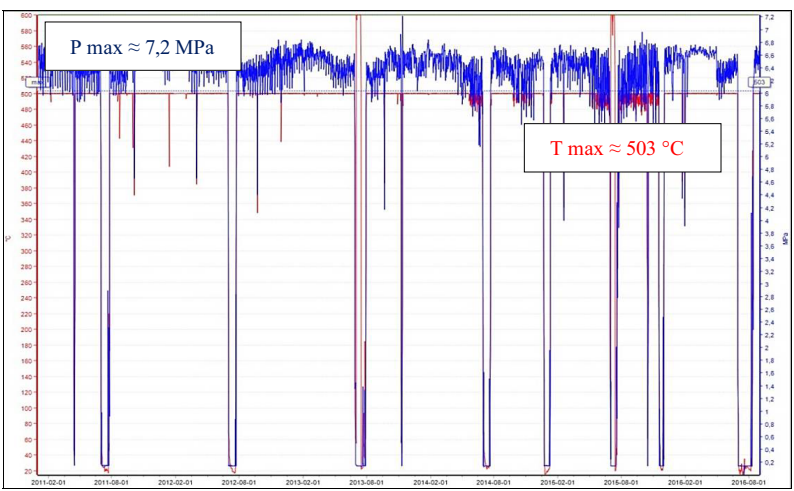

Fig. 4. Chart of steam temperature behind HP superheater II with pressure.

Table 2. Calculated and registered data.

\begin{tabular}{|c|c|c|}
\hline \multicolumn{3}{|c|}{ HP drum } \\
\hline Parameter & $\begin{array}{c}\text { Assumed } \\
\text { values }\end{array}$ & $\begin{array}{c}\text { Register } \\
\text { data }\end{array}$ \\
\hline Pressure, $\mathrm{MPa}$ & 8,4 & 7,3 \\
\hline Temperature, ${ }^{\circ} \mathrm{C}$ & 300 & 290 \\
\hline \multicolumn{3}{|c|}{ LP drum } \\
\hline Parameter & $\begin{array}{c}\text { Assumed } \\
\text { values }\end{array}$ & $\begin{array}{c}\text { Register } \\
\text { data }\end{array}$ \\
\hline Pressure, $\mathrm{MPa}$ & 1,1 & 0,68 \\
\hline Temperature, ${ }^{\circ} \mathrm{C}$ & 200 & 165 \\
\hline \multicolumn{3}{|c|}{ LP drum } \\
\hline Parameter & $\begin{array}{c}\text { Assumed } \\
\text { values }\end{array}$ & $\begin{array}{c}\text { Register } \\
\text { data }\end{array}$ \\
\hline Pressure, $\mathrm{MPa}$ & 8,4 & 7,2 \\
\hline Temperature, ${ }^{\circ} \mathrm{C}$ & 540 & 503 \\
\hline
\end{tabular}

Steam temperature and pressure values, registered by $\mathrm{LMSP}+{ }^{\circledR}$, are not exceeded for following boiler elements:

- LP drum LP,

- HP superheater II,

- HP drum.

It has also been prepared additional charts which show work of CCGT in two-shifted adjustment and change of feed water and boiler water $\mathrm{pH}$ values (lowpressure circuit). Results of analysis report show that $\mathrm{pH}$ values are close. It's very important because of magnetite layer protection durability. It allows to stop dosing boiler water alkalizer (sodium hydroxide). Charts are shown in figures 5 and 6 below.

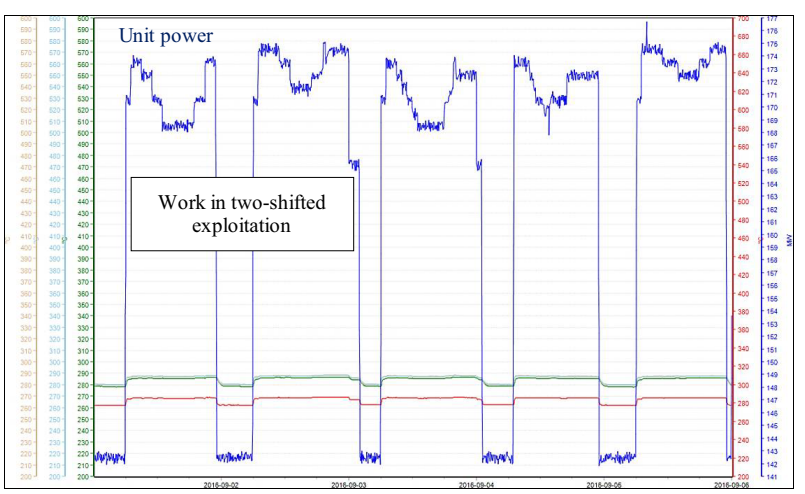

Fig. 5. Chart of drum HP metal temperature with boiler water temperature and unit power .

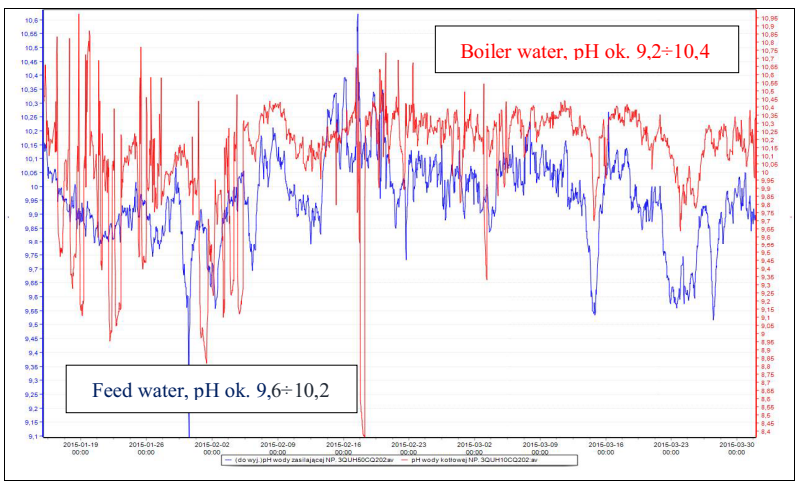

Fig. 6. $\mathrm{pH}$ values of feed water and boiler water low-pressure circuit.

\section{Retrospection of OU-192 type boiler}

After summary boiler work time, failure mainly occurred on top evaporator headers [9] and HP superheater II headers $[10,11,12]$ areas. Damages were on evaporator bend tubes (fig. 7) and welded joints connecting tubes with HP superheater II headers (fig. $8,9,10)$. This helped to create a diagnosis scope of above elements. For this purpose all available evaporator bend tubes were tested by ovalization measurement and all fillet welds were tested by magnetic particle test. Repairs were done by replacement and welding. Example damages placed below. 


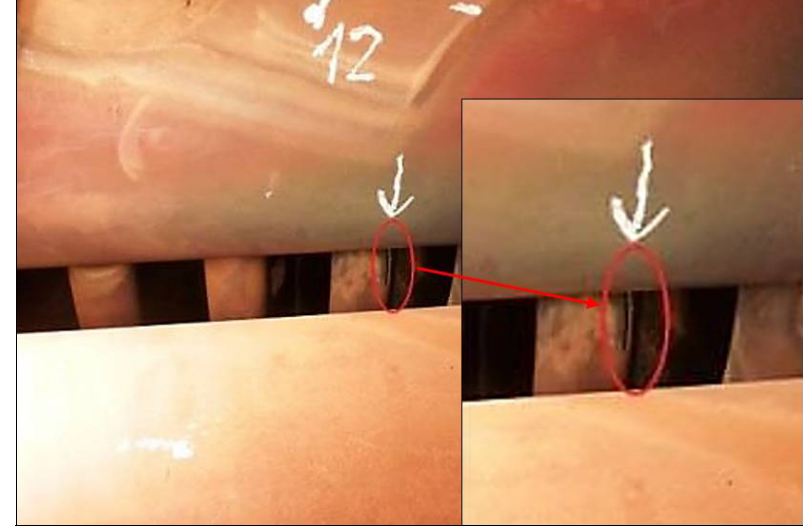

Fig. 7. Top HP evaporator headers - bend tube damage.

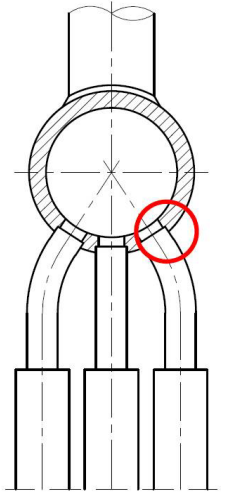

Fig. 8. Place of HP evaporator damage (bend tube section).

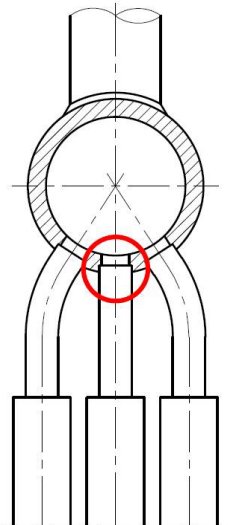

Fig. 9. Place of HP evaporator damage (straight tube section).

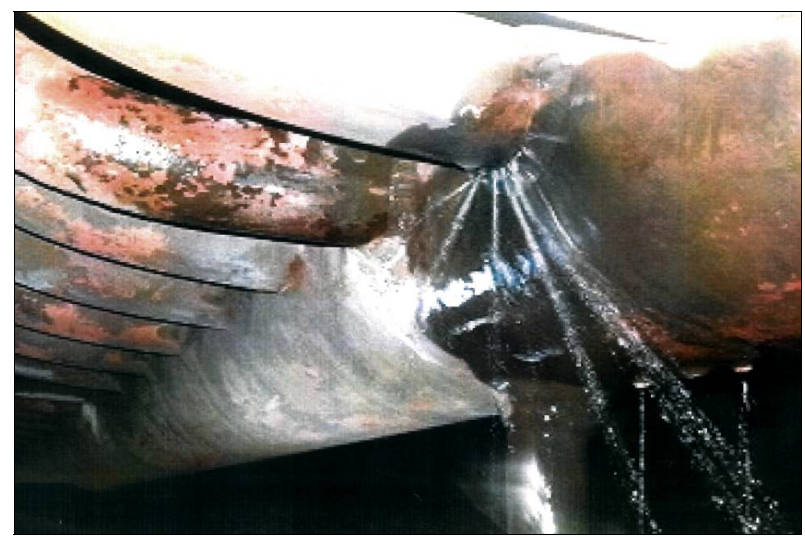

Fig. 10. Indirect (lower) HP superheater II header fillet weld damage.

\section{Overhaul of the OU-192 type boiler}

General overhaul of the boiler took place in 2016. During the 45-day repair downtime were done vitality studies on drums and thick-walled parts of the boilers due to the operating time of the boiler of approx. 100000 hours. In addition, the scope of the renovation included the action of eliminating the most frequently occurring faults of boiler pressure segments and auxiliary installations.

Overhaul scope:

- 70 bends (of all pipe coils) of the superheater SH2 were exchanged at the intersections with the lower indirect headers.

Renovation works have been conducted in accordance to executive project approved by UDT (Office of Technical Inspection). After replacing bends performed testing of $100 \%$ welded joints. Bends $\varnothing 51.6 \times 3.6 \mathrm{~mm}$ were replaced by bends $ø 51.6 \times 6.3 \mathrm{~mm}$ with material $13 \mathrm{CrMo} 4-4$.

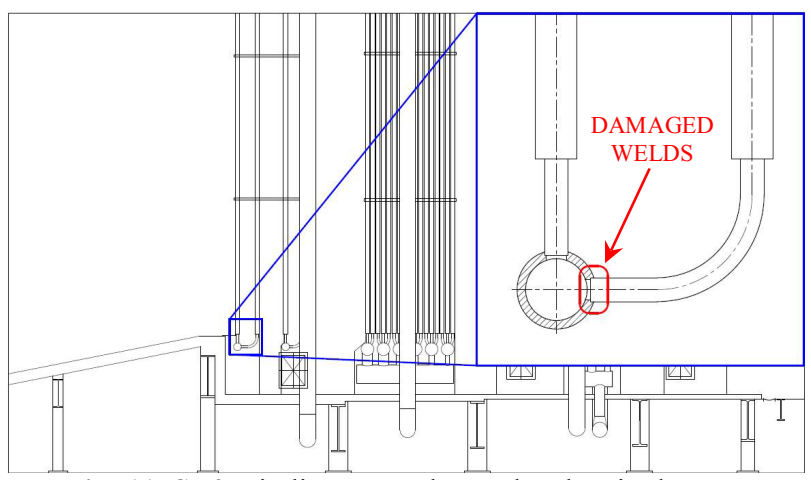

Fig. 11. $\mathrm{SH} 2$ - indirect superheater headers in the area of damage.

- Completing the installation of inspection hatches on the top and bottom of the boiler (design and installation).

Installation of the external inspection hatches has been completed (fig. 12) due to the difficult access to the individual modules of the boiler during previous shutdowns and when troubleshooting an evaporator in 2014.

As a result, in the years 2015-2016, 3 hatches was installed:

- made 2 new hatches: the level $+18 \mathrm{~m}$ side wall, the level +24 m ceiling under HR drum,

- expanded inspection hatch at $0 \mathrm{~m}$ level, which will allow to build scaffolding. 


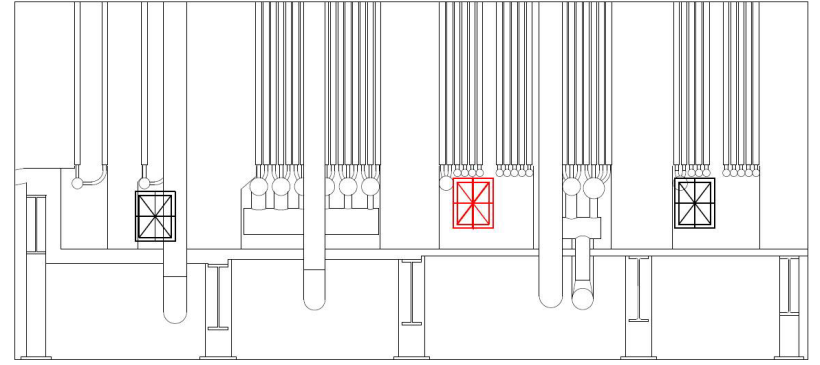

Fig. 12. Enlarged hatch in the bottom part of the boiler.

- Installation of surveying benchmarks on steam pipelines for the possibility of measuring the position of pipelines.

Work proceeded according to prepared by "Pro Novum" benchmarks deployment project for:

- low-pressure pipeline from the outlet header (including the same header) to the hull of HP/LP steam turbine,

- pipeline from the outlet header to the tee and from the tee to the reduction-boot station.

In total 31 benchmarks installed.

- Replacement of fabric expansion joints connecting the boiler to the gas turbine and boiler to the chimney.

During the renovation listed two fabric expansion joints with dimensions of $7606 \times 20108 \mathrm{~mm}$ (turbine - boiler) and $3552 \times 7942 \mathrm{~mm}$ (outlet duct - chimney). Also the internal plating in the intake duct between the gas turbine and the boiler was repaired. After completion of the work the tightness test during the commissioning of the boiler was performed.

- Completion of the modernization of boiler blowdown system.

Modernization of the boiler blowdown system and the discharge of desalination was made due to determining the presence and transport of solids called wandering oxides in water-steam system of the boiler.

- Installation of surveying benchmarks on steam pipelines for the possibility of measuring the position of pipelines

Work proceeded according to prepared by "Pro Novum" benchmarks deployment project for:

- low-pressure pipeline from the outlet header (including the same header) to the hull of HP/LP steam turbine,

- pipeline from the outlet header to the tee and from the tee to the reduction-boot station.

In total 31 benchmarks installed.
- $\quad$ Replacement of fabric expansion joints connecting the boiler to the gas turbine and boiler to the chimney.

During the renovation listed two fabric expansion joints with dimensions of $7606 \times 20108 \mathrm{~mm}$ (turbine - boiler) and $3552 \times 7942 \mathrm{~mm}$ (outlet duct - chimney). Also the internal plating in the intake duct between the gas turbine and the boiler was repaired. After completion of the work the tightness test during the commissioning of the boiler was performed.

- Completion of the modernization of boiler blowdown system.

Modernization of the boiler blowdown system and the discharge of desalination was made due to determining the presence and transport of solids called wandering oxides in water-steam system of the boiler.

\section{Diagnostics of the OU-192 type boiler}

Analysis of the parameters recorded by the LM System $\mathrm{PRO}+{ }^{\circledR}$ for adherence to established parameters and possible overruns the limit values, as well as reports from previous diagnostic tests and collected information about failures allowed to select the range of diagnostic tests involving the critical elements and places of their potential damage. The area of diagnostic testing carried out during the planned shutdown included LP and HP circuits of the boiler, as well as LP and HP steam pipelines.

Elements selected for testing [13]:

- LP drum,

- LP main outlet header,

- HP evaporator,

- HP steam superheater I,

- HP steam superheater II,

- HP main outlet header.

Scope of non-destructive testing of boiler elements [13]:

- visual and endoscope inspection,

- magnetic particle inspection,

- metallographic testing (replica),

- hardness measurement,

- ultrasonic measurement of wall thickness,

- ultrasonic measurement of the oxide layer thickness on the inner surface,

- roundness measurement.

Magnetic particle testing showed cracks on the cylindrical surface of one of the holes in water area of LP drum, on the fillet welds of the separator elements in LP and HP drums, on the fillet weld of the HP evaporator header and on the main steam header. The results of other tests have confirmed accordance with the limit values recommended by standards. Life fraction consumed level obtained on the basis of the microstructure is as follows [9]: 
- $20 \%$ for the LP and HP drums,

- $20 \%$ for the LP main steam header,

- $30 \%$ for the HP steam superheater I,

- $30 \%$ fo the HP main steam header,

- $35 \%$ for the HP steam superheater II.

\section{SUMMARY}

Gas-steam units, especially those that use fuel with an attractive price and are well-suited to the local heat market can be an attractive part of the national energy system (KSE). It is possible due to the high efficiency of generation of electricity and heat, less nuisance to the environment and high flexibility, which means that it can also act as stabilizer of the KSE. Flexible work has, however, always a price in the form of reduction in durability, especially the elements of a heat recovery boiler. To fully exploit advantages of gas-steam systems we should ensure their reliability and availability through the overhaul and diagnostics policy adapted to the conditions of specific units. Not only working conditions can be monitored continuously, but also the current technical conditions which may contribute the reduction of failure. That means lower maintenance costs and less loss of production.

Planned and systematic diagnostics and overhaul should be conducted in accordance with the knowledge of the device. Based on the analysis of the failure, you can type nodes with increased fault level under their individual program of research and modernization, in order to eliminate design errors leading to increased reliability and availability.

\section{References}

1. Kehlhofer R. : Combined-cycle gas \& steam turbine power plants. PennWell Publishing Company 1997.

2. Anderson J.: Flow-accelerated corrosion in HRSGs. AEP Plant engineering programs, 2009.

3. Jackson P., Moelling D., Anderson F., Malloy J.: Operating experience of large reheat HRSGs in merchant service. Tetra Engineering Group/Tetra Engineering Europe. Source: www.tetra-eng.com

4. Pearson M., Anderson R. : Measurement of damaging thermal transients in F-Class horizontal HRSGs. ETD International Seminar in Cyclic Operation of Heat Recovery Steam Generators (HRSGs), June 24 2005, in London, UK.

5. EPRI - Field Guide: Boiler Tube Failure 1017471 Final Report, December 2009.

6. www.wydawnictwo-gorscy.pl/pdf/bgp_folder.pdf - website.

7. www.ec.zgora.pl/technologia/urzadzenia-wytworcze - website.

8. Pro Novum Ltd. - Report LM System PRO $+{ }^{\circledR}$ no 21.1591/2015 - unpublished elaboration.

9. Pro Novum Ltd. - Technical Opinion no 022.1081/2015 - unpublished elaboration.
10. Pro Novum Ltd. - Report no 014.1973/2007 unpublished elaboration.

11. Pro Novum Ltd. - Report no 014.2000/2007 unpublished elaboration.

12. Pro Novum Ltd. - Report no 072.2952/2013 unpublished elaboration.

13. Pro Novum Ltd. - Report no 080.3395/2016 unpublished elaboration.

14. IMIA Working group paper 91 (15): Combined Cycle Power Plants. IMIA Annual Conference 2015, Merida (Yucatan), Mexico.

15. Bain D., Christophersen D. : Some common mechanisms leading to failures in heat recovery steam generators Source:www.veoliawatertech.com

16. Wojtkiewicz R.: Difficulties in removing failures and in examination of heat recovery boilers for example of OU 192 heat recovery boiler failure. „Pro Novum” Conference - Katowice, October, 2015. 